\title{
SOROEPIDEMIOLOGIA DE Neospora caninum E Toxoplasma gondii EM BOVINOS DA RAÇA CURRALEIRO
}

\section{CURRALEIRO CATTLE BREED HEALTH STATUS FOR NEOSPOROSIS AND TOXOPLASMOSIS}

\author{
Ana Paula Iglesias Santin ${ }^{1^{*}}$ \\ Raquel Soares Juliano ${ }^{2}$ \\ Andréa Caetano Silva ${ }^{1}$ \\ Vanessa Silvestre Ferreira de Oliveira ${ }^{1}$ \\ Ana Paula Junqueira-Kipnis ${ }^{1}$ \\ Wilia Marta Elsner Diederichsen de Brito ${ }^{1}$ \\ Maria Clorinda Soares Fioravanti ${ }^{1}$ \\ 1Universidade Federal de Goiás, Goiânia, GO, Brasil \\ ${ }^{2}$ Empresa Brasileira de Pesquisa Agropecuária, EMBRAPA - Pantanal, Corumbá, MS, Brasil \\ *Autora para contato - apisantin@gmail.com
}

\section{Resumo}

Este estudo comparou a soroprevalência de $N$. caninum e T. gondii em bovinos Curraleiros ao de outras raças bovinas (Nelore, Girolando, Guzerá e Caracu). Foram utilizadas 119 fêmeas bovinas adultas provenientes de quatro propriedades localizadas nos estados de Goiás e Tocantins e na divisa entre Goiás, Minas Gerais e Bahia. Animais soropositivos para N. caninum foram encontrados em todas as propriedades e o número de Curraleiros reagentes foi significativamente maior em relação aos bovinos Guzerá e Nelore. Também foram identificados anticorpos anti-T. gondii nos animais em todas as propriedades. A prevalência de soropositivos para T. gondii foi semelhante entre Curraleiros e bovinos das raças Nelore, Girolando e Guzerá; entretanto, foi significativamente maior em relação à raça Caracu.

Palavras-chave: bovino; neosporose; Pé-duro; raças locais; toxoplasmose.

\begin{abstract}
This study compared the health status of Curraleiro cattle and other breeds (Nellore, Girolando, Guzera, and Caracu) for toxoplasmosis and neosporosis screening against anti-Neospora caninum and anti-Toxoplasma gondii antibodies, respectively. We used 119 female bovines of Curraleiro, Guzera, Nellore, Caracu, and Girolando breeds from four farms in Goias and Tocantins states and in the border of Goias, Minas Gerais, and Bahia states. All the farms had seropositive bovines for $N$. caninum. The number of seropositive Curraleiro cattle was significantly higher than the number of Guzera and Nellore cattle. Also, antibodies against toxoplasmosis were found in animals from all properties. There was no significant difference between the number of seropositive Curraleiro cattle
\end{abstract}


and the breeds Nellore, Girolando, and Guzerá; however, it was significantly higher than the number of seropositive animals of Caracu breed.

Keywords: bovine; local breeds; neosporosis; "Pe-duro"; toxoplasmosis.

Recebido em: 15 dezembro de 2016

Aceito em: 03 abril de 2017

\section{Introdução}

Os primeiros bovinos foram trazidos ao Brasil no século XVI. Ao longo dos tempos, os animais sofreram um processo de seleção natural e adaptaram-se às condições tropicais dando origem ao gado Curraleiro (Bos taurus ibericus) também conhecido como Pé-duro. Esta raça caracteriza-se pela rusticidade, baixa exigência nutricional e pequeno porte ${ }^{(1,2)}$. Com a introdução de raças bovinas exóticas no século XX, o Curraleiro quase foi extinto; contudo, devido à sua rusticidade, estes animais conseguiram e ainda são capazes de sobreviver em condições precárias, diferentemente daqueles geneticamente melhorados, que, em situações semelhantes, têm seu desempenho e estado sanitário $\operatorname{comprometidos}^{(3)}$. Portanto, faz-se necessário o estudo de algumas parasitoses, como a neosporose e a toxoplasmose, na raça Curraleira em comparação a outras raças.

A neosporose vem se destacando como importante doença reprodutiva na pecuária, acarretando perdas econômicas significativas, associadas à redução da produção de leite, descarte prematuro de animais soropositivos, aborto e nascimento de bezerros fracos e inviáveis ou persistentemente infectados $^{(4)}$. A enfermidade tem distribuição mundial sendo relatada ocorrência do parasito ou de anticorpos séricos anti- $N$. caninum em caninos e bovinos, entre outras espécies ${ }^{(5)}$. Amaral et al. ${ }^{(6)}$ considera a raça do bovino, principalmente em relação ao tipo de produção ao qual é destinada, como um fator de risco.

A toxoplasmose é uma zoonose de distribuição mundial causada por T. Gondii ${ }^{(7)}$. Apesar de os bovinos serem considerado bastante resistente ao parasito, a carne bovina contaminada com cistos parasitários pode ser fonte de infecção para os seres humanos ${ }^{(8)}$. As diferentes raças podem influenciar a soropositividade ${ }^{(9)}$.

O objetivo deste estudo foi avaliar comparativamente a resposta sorológica de bovinos Curraleiros em relação a outras raças frente a enfermidades causadas por $N$. caninum e T. gondii.

\section{Material e Métodos}

As amostras deste estudo constituíram-se de 119 soros de fêmeas bovinas clinicamente saudáveis (amostra de conveniência), com mais de 24 meses de idade, colhidas aleatoriamente em quatro propriedades, selecionadas junto à Associação Brasileira de Criadores do Gado Curraleiro (ABCGC) 
por criarem gado Curraleiro juntamente com bovinos de outras raças (Tabela 1): Guzerá (Leopoldo de Bulhões, Goiás), Girolando (Planaltina de Goiás, GO), Nelore (Porto Nacional, Tocantins) e Caracu (Fazenda Trijunção, na divisa entre os Estados de Goiás, Minas Gerais e Bahia).

Tabela 1. Identificação das propriedades e número de bovinos de cada propriedade de acordo com a raça, número total de bovinos por propriedade e número total de animais da amostra, submetidos a testes sorológicos para detecção de Neospora canimum e Toxoplasma gondii

\begin{tabular}{lccccc}
\hline \multicolumn{1}{c}{ Propriedade } & Raça & $\begin{array}{c}\mathbf{N}^{\circ} \text { de } \\
\text { animais }\end{array}$ & Raça & $\begin{array}{c}\mathbf{N}^{\circ} \text { de } \\
\text { animais }\end{array}$ & Total \\
\hline Leop. de Bulhões-Prop. 1 & Curraleiro & 15 & Guzerá & 15 & 30 \\
Planalt. de Goiás-Prop 2 & Curraleiro & 14 & Girolanda & 15 & 29 \\
Porto Nacional-Prop. 3 & Curraleiro & 15 & Nelore & 15 & 30 \\
Trijunção-Prop. 4 & Curraleiro & 15 & Caracu & 15 & 30 \\
\hline Total & Curraleiro & 59 & Outras & 60 & 119 \\
\hline
\end{tabular}

Em Goiás e Tocantins havia, no momento do estudo, um total de 43 criatórios de Curraleiros; portanto, o número de propriedades que fizeram parte deste trabalho corresponde a aproximadamente $5 \%$ do total. O efetivo populacional de bovinos Curraleiros desses mesmos Estados correspondia, à época, a aproximadamente 3.000 cabeças. Em outras palavras, a amostra foi representativa de $2 \%$ de toda a população, incluindo machos e bezerros. Ao se considerarem somente as fêmeas, o tamanho da amostra foi superior a $5 \%$ do universo estudado.

A detecção de anticorpos anti- $N$. caninum foi realizada em amostras de soro diluídas a 1:100, pelo método de EIE. Foi utilizado como antígeno o extrato solúvel de taquizoítos Nc-1, desenvolvido pelo laboratório de protozooses digestivas e reprodutivas do Departamento de Sanidade Animal da Faculdade de Veterinária da Universidad Complutense de Madrid (UCM).

Nas placas de poliestireno, foram adicionados $100 \mu \mathrm{L}$ de antígeno previamente diluído em tampão Carbonato-Bicarbonato $0,1 \mathrm{M}(\mathrm{pH}=9,6)$, para que $0,2 \mu \mathrm{g}$ de proteína estivesse fixada em cada poço. Após ficarem prontos para uso, $100 \mu \mathrm{L}$ dos soros a serem previamente testados foram diluídos em PBS-Tween 0,05\% - BSA 1\% e adicionados em cada poço já antigenado em diluição de 1:100. Após a lavagem, $100 \mu \mathrm{L}$ de conjugado comercial anti-bovino (anti-bovine IgG1 e IgG2 policlonal Hipra S.L.) marcado com enzima peroxidase foram diluídos em PBS-Tween 0,05\%, a uma diluição de 1/4000, e adicionados a cada pocinho. A leitura das placas foi realizada em filtro de $405 \mathrm{~nm}$, no espectrofotômetro (Biotec@).

Para a interpretação dos resultados, foi empregado o valor IRPC (índice relativo x 100) de cada amostra. As provas foram consideradas válidas quando a DO405 média do controle positivo foi superior a 0,9 e até $\geq$ cinco vezes a DO405 média do controle negativo.

Para detecção de anticorpos anti-toxoplasma utilizou-se o ensaio imunoenzimático ELISA método indireto (Figura 3). Foram adicionados a cada cavidade das microplacas $100 \mu \mathrm{L}$ de antígeno de T.gondii diluído em tampão carbonato-bicarbonato de sódio 0,05 M pH 9,6. A concentração de 
proteína foi ajustada para $8 \mu \mathrm{g} / \mathrm{mL}$. Após três lavagens, $100 \mu \mathrm{L}$ dos soros teste e os soros de referência positivo e negativo foram ensaiados em duplicata diluídos (1:200). Uma alíquota de 100 $\mu \mathrm{L}$ do conjugado (Sigma Chemical Company, A - 0705, St.Louis, USA), constituído de $\gamma$ - globulina de coelho anti-IgG bovina marcado com fosfatase alcalina ( Sigma A - 0705), diluída a 1:30.000, foi adicionada a cada cavidade. Após a lavagem, foram adicionados a cada cavidade das microplacas 100 $\mu \mathrm{L}$ de substrato da enzima fosfatase alcalina pNPP (p-nitrofenil fosfato) diluído a $1 \mathrm{mg} / \mathrm{mL}$ em tampão dietanolamina pH 9,8. A leitura da reação deu-se em leitor de ELISA (MRX TC Plus, Dynex Technology), filtro de $405 \mathrm{~nm}$, adotando-se como branco da reação a cavidade da microplaca que não continham soro bovino

Para o cálculo das frequências de animais soropositivos, de acordo com a raça e propriedade, foi feita estatística descritiva. O teste de qui-quadrado e teste exato de Fisher foram aplicados quando apropriados, para demonstrar eventuais diferenças entre os resultados encontrados, utilizando-se o programa de estatística GraphPad InStat (version 3.05 for Windows).

\section{Resultados e Discussão}

Por meio de informações fornecidas pelos proprietários ou funcionários dos criatórios, foi possível verificar que a vegetação nativa de todas as propriedades era caracterizada por cerrado, havendo, portanto, grande diversidade de fauna e flora. Avaliando-se a presença de mananciais e de outras espécies de animais domésticos, notou-se que em todas as fazendas havia água corrente e criação concomitante de suínos, galinhas, cães e gatos. Na propriedade 1 havia um grande número de cães, aproximadamente 10 animais, e o contato direto de outras espécies com os bovinos era quase inexistente. Em relação à vacinação em todos criatórios, os bovinos eram vacinados contra aftosa, brucelose e raiva. Nas propriedades 1, 2 e 4 também se realizava vacinação contra botulismo e carbúnculo sintomático.

Bovinos soropositivos para $N$. caninum foram observados em todas as propriedades que fizeram parte do estudo (Tabela 2). O menor índice foi observado na propriedade 1, sendo significativamente diferente quando comparado com às propriedades $3(\mathrm{p}<0,0063)$ e $4(\mathrm{p}<0,0235)$, mas não em relação à 2 .

Verificou-se um número significativamente maior de bovinos Curraleiros sororreagentes para $N$. caninum quando comparado com a raça Guzerá $(\mathrm{p}<0,0211)$ e Nelore $(\mathrm{p}<0,0001)$; entretanto, a resposta sorológica foi semelhante à da raça Caracu ( $p>0,2311)$. Por outro lado, ao compará-los com a raça Girolando, verificou-se que nesta o número de soropositivos foi significativamente maior $(\mathrm{p}<0,0225)$.

Para este estudo é difícil afirmar a causa exata dessas variações, uma vez que diversos fatores têm sido citados como de risco para o aumento da soroprevalência da neosporose nos rebanhos. $\mathrm{O}$ melhoramento genético do rebanho, a aquisição de novos bovinos e a concentração de eventos que permitam maior reunião de animais são fatores que poderiam justificar o maior número de bovinos 
soropositivos para raça Girolando, mas não para o gado Curraleiro. Alguns autores ${ }^{(10)}$ mencionam que se faz necessária a realização de mais estudos que confrontem fatores como raça e sistema de manejo para se identificarem suas influências durante o parasitismo.

Tabela 2. Número de amostras colhidas e reagentes para N.caninum pelo método de EIE indireto e para $T$. gondii por EIE, para detecção de anticorpos anti-N. caninum e anti-T. gondii, respectivamente, em rebanhos bovinos de propriedades localizadas em Goiás, Tocantins e nas divisas entre Goiás/Minas Gerais/Bahia

\begin{tabular}{lcccccccc}
\hline & \multicolumn{4}{c}{ Neospora caninum } & \multicolumn{3}{c}{ Toxoplasma gondii } \\
\cline { 2 - 9 } Propriedade & \multicolumn{2}{c}{ Outras raças } & \multicolumn{2}{c}{ Curraleiro } & \multicolumn{2}{c}{ Outras raças } & \multicolumn{2}{c}{ Curraleiro } \\
\cline { 2 - 9 } & $\mathbf{n}$ & pos (\%) & n & pos (\%) & n & pos (\%) & n & pos (\%) \\
\hline Propriedade 1 & 15 & $0(0)^{\mathrm{a}}$ & 15 & $05(33,3)^{\mathrm{b}}$ & 15 & $15(100)^{\mathrm{a}}$ & 15 & $15(100) \mathrm{a}$ \\
Propriedade 2 & 15 & $07(46,7)^{\mathrm{a}}$ & 14 & $01(7,1)^{\mathrm{b}}$ & 15 & $15(100)^{\mathrm{a}}$ & 14 & $13(92,9)^{\mathrm{a}}$ \\
Propriedade 3 & 15 & $02(13,3)^{\mathrm{a}}$ & 15 & $13(86,7)^{\mathrm{b}}$ & 15 & $14(93,3)^{\mathrm{a}}$ & 15 & $12(80)^{\mathrm{a}}$ \\
Propriedade 4 & 15 & $05(33,3)^{\mathrm{a}}$ & 15 & $08(53,3)^{\mathrm{a}}$ & 15 & $08(53,3)^{\mathrm{a}}$ & 15 & $14(93,3)^{\mathrm{b}}$ \\
Total & 60 & $14(23,3)^{\mathrm{a}}$ & 59 & $27(45,8)^{\mathrm{b}}$ & 60 & $52(86,7)^{\mathrm{a}}$ & 59 & $54(91,5)^{\mathrm{a}}$ \\
\hline
\end{tabular}

$\mathbf{n}=$ Número das amostras colhidas; $\mathbf{p o s}=$ Número de amostras positivas.

(a,b)Número de amostras positivas com letras diferentes, em uma mesma linha, representam diferença significativa $(\mathrm{p}<0,05)$ entre si.

A presença de cães domésticos nas propriedades deste estudo, mesmo que sem contato direto com os bovinos, pode ser apontada como uma das causas de contaminação. Outro estudo ${ }^{(11)}$ complementa mencionando a relação direta entre o número de cães nas fazendas e a soroprevalência de $N$. caninum nos bovinos; Nno entanto, no presente experimento, a propriedade com maior número de cães não foi a que apresentou maior soropositividade. Por outro lado, alguns pesquisadores ${ }^{(12)}$ não observaram relação entre animais soropositivos e a presença de cães. Uma explicação para essa divergência pode ser o fato de que mesmo não havendo cães em uma fazenda, existe uma grande quantidade de animais errantes e canídeos silvestres que circulam livremente entre uma propriedade e outra, disseminando os oocistos entre elas ${ }^{(5)}$.

O mais provável é que os resultados observados neste trabalho sejam consequência da transmissão vertical, que é a forma mais frequente de infecção de bovinos pelo $N$. caninum, como mencionado na literatura $^{(4,13)}$. Este fato pode explicar principalmente os índices encontrados para os bovinos Curraleiros, oriundos de rebanhos fechados, compostos de animais nascidos na sua maioria nos próprios criatórios em questão.

De acordo com os proprietários ou funcionários dos criatórios, entre os animais soropositivos pesquisados, nenhum apresentava manifestações clínicas. Observação semelhante ocorreu em estudo

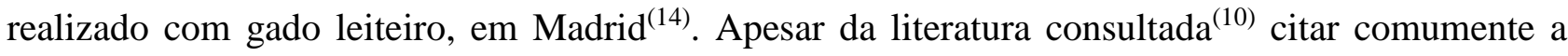
ocorrência de sinais clínicos em bovinos infectados, a existência de foco de infecção, sem sintomatologia característica, demonstra a possibilidade de a prevalência dentro do rebanho aumentar sem ser notada ${ }^{(5)}$.

As propriedades 1 e 2 podem ter apresentado menor índice de soropositividade devido a parâmetros relacionados diretamente com a ocorrência do $N$. caninum e podem refletir em uma maior ou menor 
pressão de infecção no habitat do bovino, conforme já relatado por Juliano ${ }^{(15)}$. Além disso, o fator raça parece não ter influenciado na resposta sorológica para o $N$. caninum em bovinos deste experimento.

Anticorpos anti-T. gondii também foram observados em todas as propriedades analisadas (Tabela 2). A diferença de soropositividade foi significativa somente entre as propriedades 1 e 4 ( $p<0,0023)$. As respostas sorológicas foram semelhantes entre bovinos da raça Curraleio e Nelore ( $>00,2989)$, Girolando e Guzerá ( $p>0,4828$ ). Todavia, na propriedade 4, o número de Curraleiros sororreagentes foi significativamente maior que o de bovinos Caracu $(\mathrm{p}<0,0176)$.

Neste estudo foi observada diferença na resposta sorológica para $T$. gondii apenas entre as raças Curraleiro e Caracu. Analisando os dados de uma forma mais ampla e associando os elevados índices encontrados a outros aspectos epidemiológicos observados, esta discrepância provavelmente deve ser atribuída a fatores outros que não de origem genética. Alguns pesquisadores ${ }^{(16)}$ afirmam que a associação de fatores sócio-culturais, características geográficas e climáticas e as diferenças de manejo podem justificar as variações dos índices sorológicos para este agente.

Em todas as propriedades foi relatada a presença de gatos, o que pode ter contribuído para a ocorrência da infecção por $T$. gondii, já que a transmissão de $T$. gondii para o bovino ocorre principalmente devido à presença de gatos infectados ${ }^{(17)}$.

Os animais deste estudo eram criados extensivamente, ficando expostos a pastagens que poderiam ter sido contaminadas por gatos e felídeos silvestres, tendo estes grande importância para a disseminação do parasito entre os herbívoros ${ }^{(18,19)}$.

Outra possiblidade de infecção pode ter ocorrido pela ingestão de água corrente ou de reservatórios contaminados com oocistos do T. gondii, sendo a água contaminada importante fonte de infecção para bovinos ${ }^{(20)}$. Esta hipótese ganha força já que em todas as propriedades os animais tinham acesso a cursos d'água.

\section{Conclusões}

Os resultados sorológicos para neosporose e toxoplasmose foram aparentemente semelhantes entre animais da raça Curraleiro e bovinos de outras raças.

\section{Referências}

1. Mariante A da S, Cavalcante N. Animais do descobrimento: raças domésticas da história do Brasil [Internet]. Embrapa-Assessoria de Comunicação Social: Embrapa Recursos Genéticos e Biotecnologia; 2000 [cited 2016 Dec 6]. Available from: http://www.sidalc.net/cgi$\underline{\text { bin/wxis.exe/?IsisScript=AGB } \text { xis \&method=post } \& \text { formato }=2 \& \text { cantidad }=1 \& \text { expresion }=m f n=205041}$ 
2. Britto C, Mello MLS. Morphological dimorphism in the Y chromosome of" pé-duro" cattle in the Brazilian State of Piauí. Genet Mol Biol. 1999;22(3):369-373.

3. Bianchini E, McManus C, Lucci CM, Fernandes MCB, Prescott E, Mariante A da S, et al. Características corporais associadas com a adaptação ao calor em bovinos naturalizados brasileiros. Pesqui Agropecu Bras. 2006;41(9):1443-1448.

4. Santana RCM, Massa R, Zafalon LF, Megid J, Langoni H, Mathias LA. Estudo epidemiológico sobre as perdas reprodutivas em bovinos leiteiros: ocorrência de Neospora Caninum, Brucella Abortus, Herpesvírus Bovino Tipo-1 e Leptospira Spp. em uma propriedade do Município de São Carlos-SP. Ars Vet. 2013;153160.

5. Goodswen SJ, Kennedy PJ, Ellis JT. A review of the infection, genetics, and evolution of Neospora caninum: from the past to the present. Infect Genet Evol. 2013;13:133-150.

6. Amaral RL, Silva LB, Júnior JWP, Neto OLS, Leal CA, Porto WJ, et al. Neospora caninum em bovinos em matadouros de Pernambuco e Alagoas. Pesqui Veterinária Bras. 2012;32(10):963-966.

7. Dubey JP. A review of toxoplasmosis in cattle. Vet Parasitol. 1986;22(3):177-202.

8. Santos SL, de Souza Costa K, Gondim LQ, da Silva MSA, Uzêda RS, Abe-Sandes K, et al. Investigation of Neospora caninum, Hammondia sp., and Toxoplasma gondii in tissues from slaughtered beef cattle in Bahia, Brazil. Parasitol Res. 2010;106(2):457-461.

9. Moura AB, Osaki SC, Zulpo DL, Garcia JL, Teixeira EB. Detecção de anticorpos contra Toxoplasma gondii em bovinos de corte abatidos em Guarapuava, PR, Brasil. Arch Vet Sci. 2010;15(2):94-99.

10. dos Anjos Santos I, de Magalhães VCS, Costa SCL, Munhoz AD. Avaliação dos índices zootécnicos em vacas mestiças com Neospora caninum no sudeste da Bahia, Brasil: uma análise em um rebanho leiteiro. [cited 2016 Dec 6]; Available from: http://www.rbmv.com.br/pdf artigos/17-12-2014 19-01RBMV089.pdf

11. Martins NÉX, Freschi CR, Baptista F, Machado RZ, Freitas FL da C, Almeida K de S. Ocorrência de anticorpos anti-Neospora caninum em vacas lactantes do município de Araguaína, estado do Tocantins, Brasil. Rev Patol Trop. 2011;40(3):231-238.

12. Aguiar DM, Cavalcante GT, Rodrigues AA, Labruna MB, Camargo LMA, Camargo EP, et al. Prevalence of anti-Neospora caninum antibodies in cattle and dogs from Western Amazon, Brazil, in association with some possible risk factors. Vet Parasitol. 2006;142(1):71-77.

13. Hein HE, Machado G, Miranda IC, Costa EF, Pellegrini DC, Driemeier D, et al. Neosporose bovina: avaliação da transmissão vertical e fração atribuível de aborto em uma população de bovinos no Estado do Rio Grande do Sul. Pesqui Veterinária Bras. 2012;32(5):396-400.

14. Rojo-Montejo S, Collantes-Fernández E, Regidor-Cerrillo J, Álvarez-García G, Marugan-Hernández V, Pedraza-Díaz S, et al. Isolation and characterization of a bovine isolate of Neospora caninum with low virulence. Vet Parasitol. 2009;159(1):7-16.

15. Juliano RS. Aspectos sanitários e do sistema de fagócitos de bovinos da raça Curraleiro [Internet]. Tese (Doutorado em Ciência Animal)-Escola de Veterinária, Universidade Federal de Goiás, Goiânia; 2006 [cited 2016 Dec 6]. Available from: https://portais.ufg.br/up/67/o/Tese2006_Raquel_Juliano.pdf

16. Heil Lopes CC, Berto BP. Aspectos associados à toxoplasmose: Uma referência aos principais surtos no Brasil. Saúde Ambiente Em Rev. 2013;7(2):1-7.

17. Albuquerque GR, Munhoz AD, Teixeira M, Flausino W, Medeiros SM, Lopes CWG. Risk factors associated with Toxoplasma gondii infection in dairy cattle, State of Rio de Janeiro. Pesqui Veterinária Bras. 2011;31(4):287-290. 
18. Luciano DM, Menezes RC, Ferreira LC, Nicolau JL, Neves L das, Luciano RM, et al. Soroepidemiologia da toxoplasmose em caprinos e ovinos de três municípios do Estado do Rio de Janeiro. Pesqui Vet Bras. 2011;31(7):569-574.

19. Carneiro BF, Miranda MM de, Silveira Neto OJ da, Linhares GFC, Araújo LB de M. Inquérito sorológico para toxoplasma gondii em mamíferos neotropicais mantidosno centro de triagem de animais silvestres, Goiânia, Goiás. 2014 [cited 2016 Dec 6]; Available from: http://repositorio.bc.ufg.br/handle/ri/4096

20. Moura LD, Oliveira LMGB, Wada MY, Jones JL, Tuboi SH, Carmo EH, et al. Waterborne toxoplasmosis, Brazil, from field to gene. 2006 [cited 2016 Dec 6]; Available from: http://repositorio.unb.br/handle/10482/11464 